Mavi Atlas, 5(2)/2017: 549-576.

Araştırma Makalesi | Research Article

Makale Geliș | Received: 14.09.2017

Makale Kabul | Accepted: 27.09.2017

DOI: $10.18795 /$ gumusmaviatlas.357453

Engin GÖKÇÜR

Yrd. Doç. Dr. | Assist. Prof. Dr. Gümüşhane Üniversitesi, Edebiyat Fakültesi, Türk Dili ve Edebiyatı Bölümü, Gümüşhane-Türkiye Gümüşhane University, Faculty of Letter, Dep. of Turkish Language and Literature, Gümüşhane-Turkey

orcid.org/0000-0002-8403-4763

engingokcur@gumushane.edu.tr

\title{
Türkmen Türkçesinde İkincil Uzun Ünlüler Üzerine
}

$\ddot{O} z$

Türkmen Türkçesinin en karakteristik özelliklerinden biri Ana Türkçedeki aslî uzun ünlüleri büyük oranda korumuş olmasıdır. Sözcüklerin aslî yapısında olmayıp daha sonraları çeşitli ses olayları neticesinde uzamaya maruz kalan ünlülere ikincil uzun ünlü diyoruz. Türk dilinin tarihi dönemlerinde ek ve sözcük düzeyinde kullanılan birçok şekil Türkmen Türkçesine uzanan süreçte ses düşmeleri ve ekleşmeler neticesinde değişikliğe uğramış, neredeyse tanınmayacak bir duruma gelmiştir. Eklerin ve sözcüklerin oluşan yeni şekillerinde düşen seslerin yükünü üstlenen ünlülerin uzamaya maruz kaldığı görülür. Türkmen Türkçesinde gerek sözcük köklerinde ve gerekse de kök-ek birleşmeleri esnasinda oluşan uzun ünlülerin değişik nedenleri vardır. İkincil uzun ünlülerin oluşumunda bazen sözcük kök ve gövdelerindeki ses düşmeleri bazen de hece kaynaşmalarının etkili olduğu görülür. Aynı zamanda özellikle kök-ek birleşmelerinde hece kaynaşmalarının, eklere pekiştirme amacı yapılan vurguların da uzun ünlülerin oluşumunda etkili olduğunu söyleyebiliriz.

Anahtar Kelimeler: Türkmen Türkçesi, İkincil Uzun Ünlü, Hece Kaynaşması, Ses Düşmesi.

\section{Upon Secondary Long Vowels in Turcomen Turkish}

\begin{abstract}
One of the most characteristic peculiarity of Turcomen Turkish is that it has greatly protected the main long vowels in main Turkish. Not having been in main construction of words, but as a result of different vowel events the vowels having been exposed to be longer ones are called secondary long vowels by us. Many forms at a level of affix and word in historical periods of Turkish language have changed as a result of affixations and omissions within the period of Turkmen Turkish and nearly become unrecognizable. Vowels that take the task of omission of affixes and words in new forms are exposed to change. There are several reasons of long vowels which either being formed in origin of vowels or during connection of origin- suffix. In composing of secondary long vowels sometimes omiting of voice in construction and sometimes syllables's is coming together have been effective. We can say that especially syllables's coming together in connection of origin-suffix and stress that aims to strengthen suffix are effective in composing of long vowels.
\end{abstract}

Keywords: Turcomen Turkish, Secondary Long Vowels, Syllable Fusion, Omiting of Sounds. 


\section{Giriş}

Bir dilin ilk yazılı kaynaklarında normal süreli olup daha sonradan bir ses olayı neticesinde değişikliğe uğramış, boğumlanma süreleri normal süreli ünlülere göre daha uzun olan ünlülere ikincil uzun ünlü diyoruz. İkincil uzun ünlüler çoğunlukla ses düşmelerine bağlı olarak ortaya çıkar. Sözcüklerdeki seslerin düşmelerinde iki ünlünün, bir ünlü ile bir ünsüzün, bir ünlü ile iki ünsüzün, iki ünsüz ile bir ünlünün boğumlanma sürelerinin birleşmesinden ortaya çıkar. Hece kaynaşmasına bağlı olarak ortaya çıkan ikincil uzun ünlüler ise genellikle iki ya da daha çok hecenin kaynaşması neticesinde oluşur. İkincil uzun ünlüleri aşağıda belirtildiği üzere yedi alt başlık altında incelemeyi uygun gördük:

1. Ünsüz Yitimi Sonucu Oluşan Uzun Ünlüler

2. Hece Kaynaşması Sonucu Oluşan Uzun Ünlüler

3. Ünlü Karşılaşması Neticesinde Ortaya Çıkan Uzun Ünlüler

4. Ekleşme Durumunda Oluşan Uzun Ünlüler

5. Daima Uzun Ünlülü Ekler

6. Sözcük Birleşmeleri Neticesinde Oluşan Uzun Ünlüler

7. Ayınlı ve Hemzeli Uzunluklar

\section{1. Ünsüz Yitimi Sonucu Oluşan Uzun Ünlüler}

Ünlü uzamalarına sebep olan ünsüzler genellikle iç ve son seste bulunan b, g, $\breve{g}$, h, k, l, n/ ñ r, v, y ünsüzleridir. Bu ünsüzlerden b, k > g/ğg, ñ > w, v ya da y ünsüzlerine dönüşerek yarım ünlü oluşturur. Daha sonraları bu yarım ünlüler yanlarındaki ünlülerle ilk önce ikiz ünlü oluşturur. Akabinde bu ünlüler birleşerek uzun bir ünlü haline gelir. Ayrıca "r ve l" ünsüzleri de söyleyiş zorluğu ve akıcı ünsüzler oluşlarından dolayı düşmeye yatkın sesler olmaları yönüyle zamanla düşme eğilimi gösterir. Düşen bu ünsüzlerin yükünü alan ünlülerin uzadığg görülür (Buran 2006: 4).

Türkmen Türkçesinde sözcük kök ve gövdelerinde oluşan ünlü uzunluklarında temel etmen yarım ünlü değerindeki /v/, / $\breve{g} /, / y /$ ve $/ \mathrm{h} /$ ünsüzlerinin erimesi hadisesidir. $\mathrm{Bu}$ ünsüzlerin düşmesi neticesinde ünlüler kendilerinden önce ya da sonra düşen 
ünsüzlerin yükünü üstlenerek uzamıştır. Türkmen Türkçesinde ünsüz erimesi neticesinde oluşan uzun ünlüleri aşağıdaki alt başlıklarda inceledik:

\section{1. b Erimesi Sonucu Oluşan Uzun Ünlüler}

İç ses konumundaki "b" sesinin düşmesi neticesinde düşen sesin yükünü alan ünlünün uzadığı görülür: mahaabat < Ar. maḥabbat; yuuka "yufka"< OT. yufḳa, yuwḳa, yupka, yubka.

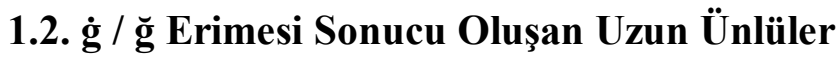

İç ses konumundaki "g" sesinin sızıcılaşıp ardından erimesi neticesinde düşen sesin yükünü alan ünlünün uzadığı görülür: puudak < boğdak.

1.2.1. “-11nçaa, -iinçää” eki Türkçenin tarihi dönemlerinde "-gınça, ginçe şekillerinde kullanılır. Ekin başındaki ünsüzün düşmesi neticesinde düşen ünsüzün yükünü üstlenen ünlünün uzadığ1 görülür. Ekin sonundaki ünlünün uzun olmasında zarf-fiil ekinin ünlüsünün yönelme hal ekiyle birleşmesi neticesinde gerçekleşmiştir (Borcakov, A. - Sarıhanov, M. - Söyegov, M. - Hocayev, B. - Ärnazarov, S. 2000: 442).

Solınçaa “soluncaya kadar”, göriinçää “görünceye kadar”. (TTS 1995: 10)

Tää ömrüñ ötinçää sılağlı boorsuñ. “Ömrün geçinceye kadar saygılı olursun.” (Gurbannepesow 1995: 94).

İndiki kitaabın açınçaa gatın / İndik yalñışım gözüm açınçaa "Bir sonraki kitabın açıncaya kadar katını / Bir sonraki yanlışım gözümü açıncaya kadar” (Kara 1997: 206).

Ey yaaraanlar tarlañ guşum uçurdum / Sağ elimden sool elime alınçaam / Nääzli yaarı̃ gurbaanıyam, gulıyam / El götermen, daamanınmdan ölüünçääm. "Ey dostlar tarla kuşumu uçurdum / Sağ elimden sol elime alıncaya kadar / Nazlı yârin kurbanıyım, kuluyum / El kaldırmayın, eteğimden ölünceye dek. (Durdıyewa 2004: 21) 


\section{3. h Erimesi Sonucu Oluşan Uzun Ünlüler}

Türkmen Türkçesinde alıntı sözcüklerin bünyesindeki iç ve son ses konumundaki “ $h$ ” ünsüzlerinin düşmesi neticesinde düşen ünsüzün yükünü alan ünlünün uzamaya maruz kaldığg görülür: TrkmT. kööne "eski” < Far. köhne; TrkmT. määkääm "muhkem” < Ar. muhkem; TrkmT. määtääç "muhtaç” < Ar. muhtâc; TrkmT. sabaa < Ar. șabah, TrkmT. sääv "sehiv, yanılma" < Ar. sehv; TrkmT. şaazaada "şehzade" < Far. şeh+zâde; TrkmT. tääsiin < Ar. taḥsiin; TrkmT. bääs "yarış, galibiyet" < Ar. bahs;; TrkmT. kääriz "yeraltı sularını değerlendirmek amacıyla yer altında yapılan su kanalı" < Far. hâk + rîz; TrkmT. gümraa "Bir şeyle aşırı meşgul olma" < Far. gumrâh / gümreh "bol, gür”; TrkmT. mitaara "matara, su kabı" < mitḥare

\section{4. ñ, n Erimesi Sonucu Oluşan Uzun Ünlüler}

İç ses konumundaki “n, ñ” ünsüzünün düşmesi neticesinde düşen ünsüzün yükünü alan ünlünün uzadığı görülür: TrkmT. yaalı < ET. yañlıg; Trkm.T. hıına "kına" $<$ Ar. hinnâ'.

1.4.1. “-kAn” zarf-fiiil eki Türkmen Türkçesinde “-kaa, -kää” şekilleriyle uzun ünlülüdür: Bu ek de "ken” zarf-fiilinin ekleşmesi neticesinde oluşmuştur. Bu ek isim ve birleşik fiil çekimlerinde "erken" şeklinin ekleşmesi neticesinde erken > -eken > -ken > kaa/kää oluşmuştur: (Borcakov, A. - Sarıhanov, M. - Söyegov, M. - Hocayev, B. Ärnazarov, S. 2000: 378).

Çaar yaanıñda gaarlar doñup yatırkaa / Issık köölde yüzüp yörmek ne hezil. “ Dört yanında karlar donup yatarken / Issık Gölü’nde yüzmek ne güzel!” (Gurbannepesow 1995: 30).

...Nazar Gaarlılara baryaarkaa yoolda aağasından zeyrendi. “... Nazar Garlılara giderken yolda ağabeyinden yakındı." (Așır 2012: 30).

...indi nääderkääk diyip oturkaalar, birden bir yerden ovaaz geldi. "Şimdi ne yaparız ki deyip otururlarken birden bir yerden ses geldi." (Kakalıyeva-Otuzov 1995: 202). 
Yeke gitmeli boldum-ov diyip duurkaam aayıñ yağtısına kööne geyimiñ içinde de bir kişice görünyään dayav yiğidiñ uuklaap yatanını sayğardım. “" 'Yalnız gideceğim.' diye düşünüp dururken ay ışığında eski kıyafetler içinde bir yiğidin yattığını fark ettim." (Kakalıyeva-Otuzov 1995: 344).

Ayıb1 yook, yatmaankaañ meniñ öñume bir goltuk göök yoruncaanı getirip dökersiñ. "Zararı yok, yatmadan benim önüme bir koltuk yeşil yoncayı getirip dökersin.” (Kakalıyeva-Otuzov 1995: 382).

\section{5. v, w Erimesi Sonucu Oluşan Uzun Ünlüler}

İç ve son ses konumundaki "v” ünsüzünün yanındaki ünlüyü yuvarlaklaştırması, akabinde düşmesi neticesinde düşen ünsüzün yükünü alan ünlünün uzadığı görülür: TrkmT. noobahar "nevbahar" < Far. nev+bahâr; TrkmT. noobat "nöbet" < Ar. nevbet; TrkmT. tooba "tövbe" < Ar. tevbe; TrkmT. moolla $<$ Ar. mevlâ.

\section{6. y Erimesi Sonucu Oluşan Uzun Ünlüler}

İç ve son ses konumundaki “y” ünsüzünün düşmesi neticesinde düşen ünsüzün yükünü alan ünlünün uzadığ1 görülür: TrkmT. gıbat "gıybet" < Ar. giybet; TrkmT. hääsiyet "özellik" < Ar. hayșiyyet; TrkmT. miive "meyve" < Far. meyve; TrkmT. şıh “şeyh” < Ar. şeyḩ; TrkmT. pı1gamber "peygamber” < Far. peygâmber.

\section{Hece Kaynaşması Sonucu Oluşan Uzun Ünlüler}

Hece kaynaşması çoğu zaman iki farklı hecenin ünlülerinin yan yana gelmesi durumunda ya da ünsüz yitimi neticesinde yan yana gelen ünlülerden birinin düşmesi sonucu oluşur. Türkmen Türkçesinde hece kaynaşması sonucu uzamaya maruz kalan ünlüleri birkaç başlık altında ele almayı uygun gördük:

\subsection{Sözcük Kök ya da Tabanlarında Ünsüz Düşmesi Neticesinde Oluşan}

\section{Uzun Ünlüler}

Türkmen Türkçesinde iç seste bulunan “b, $\mathbf{k}, \mathbf{g}, \breve{\mathbf{g}}, \mathbf{n} / \tilde{\mathbf{n}}, \mathbf{h}, \mathbf{v}, \mathbf{y}$ ” ünsüzlerinin düşmesi neticesinde bu ünsüzlerin yanlarında bulunan ünlüler ilk planda ikiz ünlü 
oluşturur. Ardından bu ikiz ünlüler hece kaynaşması neticesinde uzun ünlülere dönüşme eğilimi gösterirler.

\subsection{1. d/t Ünsüzlerinin Erimesi Sonucu Oluşan Hece Kaynaşmaları}

Sözcüklerin bünyesindeki iç ses konumundaki “d” ünsüzlerinin erimesi neticesinde yan yana gelen ünlülerin hece kaynaşması neticesinde uzadığı görülür: TrkmT. çaarşaav "çarşaf” < Far. çâder+şeb; TrkmT. käähüda " kethüda” < Far. ked + hudâ; TrkmT. uuk1 "uyku"< ET. ud1- +ku.

\subsection{2. h Ünsüzünün Erimesi Sonucu Oluşan Hece Kaynaşmaları}

İç ses konumundaki “h” ünsüzünün erimesi neticesinde yan yana gelen ünlülerin hece kaynaşması neticesinde uzadığı görülür: TrkmT. çaarçuva "çerçeve" < Far. çehar + çuube; TrkmT. çääryek "çeyrek" < Far. çehar + yek; TrkmT. paataa "fatiha" < Ar. fâtiha; TrkmT. tääret "taharet, temizlik < Ar. țahâret.

\subsection{3. g / g Ünsüzlerinin Erimesi Sonucu Oluşan Hece Kaynaşmaları}

TrkmT. baatır < Moğ. bag̉atur; TrkmT. dääl "değil” < OT. tegül / dag̉ ol.

\subsection{4. v,w Ünsüzünün Erimesi Sonucu Oluşan Hece Kaynaşmaları}

TrkmT. coomart "cömert" < Far. cevân+merd; TrkmT. aazık $<$ awuzık $<$ aguz + $1 \mathrm{k}$.

\subsection{5. y Ünsüzünün Erimesi Sonucu Oluşan Hece Kaynaşmaları}

TrkmT. uuklamak < uyuklamak.

2.1.5.1. “-maan, -mään” zarf-fiil ekleri Türkmen Türkçesinde uzun ünlülüdür. Bu ek Türkmen Türkçesinin 18 ve 19. asır metinlerinde “-mayın, -meyin” şekillerinde kullanılır:

Ak ceren aldırsa elden ovlağın

Mäley-mäley gözlemeyin bolar mı? (Magtımkulı:452)

Yağşı gezip nobatında 


\section{Ölmeyin, yaman galmadı.” (Şasenem-Garıp)}

Türmen Türkçesinde "-maan, -mään” zarf-fiil eki Türkmen Türkçesinin tarihi metinlerinde kullanılan "-mayın, -meyin" şeklinin ses düşmeleri ve ünlü birleşmesi neticesinde oluşan şeklidir. (Nartıyev 2010: 174).

Otırsiñ öyden çıkmaan. "Oturursun evden çıkmadan.” (Kara 1997: 78).

Onda sen taabıdı̃ içinde bolmaan / Taabıt seniñ peçiñ içinde boordı. "O zaman sen tabutun içinde olmadan / Tabut senin sobanın içinde olurdu." (Gurbannepesov 1995: 102).

Toya çağrılmaan barsam ol näähili bolar? "Düğüne çağrılmadan gitsem acaba nasıl olur? (Aşır 2012: 15)

Suhan gat1 Mrraat aağaanı̃ salaamını almaan söwdaasını dowaam etdi. "Katı Suhan Mrrat Ağabeyin selamını almadan alışverişine devam etti.” (Deryayev 1981: 44).

2.2. Hece düşmesi neticesinde oluşanlar: Boğumlanma noktaları birbirine yakın ünsüzlerin bir arada bulunması durumunda ya da bir ünlüyle patlayıcı, sızıc1, akıcı bir ünsüzün yan yana gelmesi halinde telaffuz güçleştiğinden önce ünsüz yitimi gerçekleşir. Ardından yan yana gelen ünlülerden biri düşer, düşen hecenin yükünü alan ünlü uzar: TrkmT. mooncuk < boyun + cuk; TrkmT. päälvaan "pehlivan" < Far. pehlevân; TrkmT. işdää "iştah" < Ar. iştihâ'; TrkmT. raayat "tabiyyet, uyruk" < Ar. ra'iyyet; TrkmT. aalaçık < alnı + açık; TrkmT. biike "kadın, kız" < beyke $<$ beg + eke.

\section{3. Ünlü Karşılaşması Neticesinde Ortaya Çıkan Uzun Ünlüler}

$\mathrm{Bu}$ grupta yer alan uzun ünlülerin oluşma sürecinde çoğunlukla ünlü karşılaşmaları etkilidir. Türkmen Türkçesinde ünlü ile biten fiil kök ya da gövdeleri yine ünlü ile başlayan bir eke ulandığında oluşan ünlü karşılaşması neticesinde ünlüler birleşerek uzun ünlünün oluşumuna sebebiyet verir. Aynı zamanda titrek "r ve 1" ünsüzleri ile biten fiillere geniş zaman eki getirildiğinde telaffuz güçleştiği için bu titrek ünsüzler düşer. $\mathrm{Bu}$ ünsüzlerin düşmesi neticesinde karşı karşıya kalan ünlüler birleşerek 
ünlü uzamasına sebebiyet verir. Bu şekilde oluşan ünlü uzunluklarını birkaç başlık altında incelemeyi uygun gördük:

3.1. Düz ünlüler ile biten sözcüklere yönelme durum eki getirildiğinde söz konusu ünlüler uzar:

Giice keşbi çaaylı kääsää meñzedi. "Gece görünüşü çaylı kâseye benzedi." (Kara 1997: 70).

Sensiz cahanda gezmenem / Senden özgää yaar diymenem "Sensiz bu dünyada gezmem / Senden başkasına yar demem." (Durdıyewa 2004: 18)

Bir goca galandar kişää sataşdım "Bir yaşlı kalender kişiye rastladım. (Kara 1997:412)

Men yağaa düşemde oon sekiz yaaşımdadım. "Ben düşmanın eline düştüğünde on sekiz yaşındaydım.” (Govşudov 1989).

Bazarı̃ çetinden giireniñden üsti göök demir bilen örtülen ullakaan beyik bassırmaa gözüñ iilyäärdi. "Pazarın bir tarafından girdiğinde üstü mavimsi bir demirle örtülmüş büyükçe bir yapıya gözün ilişirdi." (Deryayev 1981: 245).

Geldi toylı meselää / Nokat goymak çaağımız. "Geldi şölenli meseleye / Nokta koyma vaktimiz." (Kara 1997: 528).

3.2. /a/ ve /e/ ünlüleri ile biten fiillere emir kipinin teklik ve çokluk 1. kişi eki ile çokluk 2. kişi eki getirildiğinde fiillerdeki söz konusu ünlüler hece kaynaşması neticesinde uzar:

Soñra: Men öye baarıp soraayın, "Sonra: Ben eve gidip sorayım” (Durdıyewa 2006: 44).

Näädip seniñ yaalı yörääyin. "Nasıl senin gibi yürüyeyim.” (Çarıyew 2004: 88)

Gel, bir aayat okaalı. "Gel bir ayet okuyalım” (Çarıyew 2004: 54)

Ey bedasıllar meniñ guşumga degmääñ "Ey asılsızlar benim kuşuma dokunmayın!” (Durdiyewa 2004: 11) 
Men seni görmääyin "Ben seni görmeyeyim. (Kara 1997: 406)

Atalık sözümi gööğertcek bolup / Seniñ gül gövnüñe değmääyin diydim. “ 'Babalık sözümü büyütecek olup/ Senin gül gönlüne dokunmayayım.' dedim.' (Kara 1997: 224).

Yook aadamlar siz onı geñ görmääñ. "Hayır, insanlar siz ona şaşırmayın." (Çarıyew 2004: 25).

3.3. /a/ ve /e/ ünlüleri ile biten fiillere "-Ip" zarf-fiil eki getirildiğinde fiillerdeki ünlüler hece kaynaşması neticesinde uzar:

Yüzlerçe gülleri oğşaap gaçyaardı. "Yüzlerce çiçekleri okşayıp kaçardı." (Gurbannepesow 1995: 3).

Suwsaap barsañ küyze eğip, çaal guyar. "Susayıp varsan testiyi eğip ayran koyar." (Gurbannepesow 1995: 18).

$\mathrm{O}$ çöl-beyevaan bilen bir gidişine üç giice gündiizlääp yel yaalı gidipdir. "O çöllük boyunca bir gittiğinde üç gece gündüz giderek yel gibi gitmiş.” (KakalıyevaOtuzov 1995: 343).

Inhaa şo barmaana gışıñ sovuk günleriñde menden beyleki çaağalarıñ ikisi hem kesellääp, 11zlı-11zlına yooğaldı. "İşte bu gidişinde kışın soğuk günlerinde benim dışımdaki çocukların ikisi de hastalanıp, ardı ardına öldü.” (Deryayev 1981: 356).

Buu yere yetyäänçääler ençeme günlääp yol söküpdiler. "Buraya gelinceye kadar nice gün yol katetmişlerdi.” (Govşudov 1989: 456).

Giiçlääp gızar ikindi vağtları bir keyik bilen bir nääçe guş alıp geldiler. "Geç vakitte, güneşin kızaran ikindi vaktinde bir geyik ile birkaç kuş alıp geldiler." (Govşudov 1989: 535).

Soñra veziire garaap : "Bar, siziñ aydanıñı bolsun.” diyyäär. "Sonra vezire bakıp "peki, sizin dediğiniz olsun.” diyor. (Kakalıyeva-Otuzov 1995: 229). 
3.4. /a/ ve /e/ ünlüleri ile biten fiillere geniş zaman “-ar, - er” ekleri getirildiğinde hece kaynaşması neticesinde söz konusu düz ünlüler uzar:

Piğaan eyläär biziñ baağıñ bilbili "Figan eder bizim bağın bülbülü” (Durdıyewa 2004: 44)

Waay oğlanı öldürme goy häzirlikçe munda galaaysın, ölmese iir u giiç öözi hak ejesini tanaar. "Vah, çocuğu öldürme. Bırak şimdilik burada galsın, ölmezse er geç kendisi gerçek annesini tanır.” (Kakalıyeva, N.- Otuzov 2008: 425)

Baran yeriñde beydip tutulan guş yaalı bolup otursañ, bir-ää öözüñi hoorlaarsıñ, onsoñ baran yeriñem azaara goyarsın. "Gittiğin yerde böyle kafesteki kuş gibi durursan, kendine de eziyet edersin, gittiğin yerdekilere de eziyet vermiş olursun." (Govşudov 1989: 843).

Men siziñ barıp gelyäänçääñiz iycek-içceğiñizi hem üpcünläärin. "Ben gidip gelinceye kadar sizin yiyecek ve içeceklerinizi hazırlarım.” (Kerbabayev 1992: 253).

Aay diysem aaya meñzäär! diyip boğazına sığdığından gı̆̆ırdı. "Ay desem aya benzer" diyerek sesi yettiğince bağırdı." (Govşudov 1989: 234).

3.5. "r ve l" ünsüzü ile biten fiillere geniş zaman ekleri (-ar, -er) getirildiğinde çoğu zaman fiil kökündeki bu titrek ünsüzler düşer. Bu durumda karşı karşıya kalan ünlüler hece kaynaşması neticesinde uzamaya maruz kalır:

Görse bir topar aadam aaya bakıp duur eken. "Görse bir grup insan aya bakıp dururmuş." (Durdıyewa 2006: 12)

Tää ömrüñ ötinçää sıllağlı boorsuñ. “Ömrün geçinceye kadar saygılı olursun.” (Gurbannepesov 1995: 94).

Onda sen taabıdıñ içinde bolmaan / Taabıt seniñ peçiñ içinde boordı. "O zaman sen tabutun içinde olmadan / Tabut senin sobanın içende olurdu." (Gurbannepesov 1995: 102).

Uukusız otırın giicääniñ yaarı "Uykusuz otururum gece yarısı. (Kara 1997: 406) 
Öözüñizden ulınıñ yaanına geleniñizde edep bilen çöküñize düşüp otırlar. "Kendinizden büyüğü yanınıza geldiğinde edeple diz üzerine çöküp oturulur." (Deryayev 1981: 154).

Oturanları oturıpdırlar, oturmadıklar hem oturcak bolşup duurlar. "Oturanları oturmuş, oturmayanları da oturacak olup dururlar.” (Deryayev 1981: 286).

3.6. Ünlü ile biten sözcüklere “+1k, +ik” yön eki eklendiği takdirde yön ekinden önceki ünlüler hece kaynaşması neticesinde uzar:

içeriik "içer, içeriye", ileriik "ileriye doğru", añruk "öteye doğru”, bääriik “beriye doğru”, yokarık "yukarıya doğru” (TTS 1995: 12).

Yokarık galyaan menem. "Yukarı çıkıyorum ben de.” (Kara 1997: 84).

Emmaa kööz basan dek egildim aşaak. "Ama köz basılmış gibi aşağı eğildim” (Gurbannepesow 1995: 87).

Baagban salaam berip, içeriik girmääge rugsat sooradı. "Bahçıvan selam verip içeriye girmek için izin istedi.” (Kakaliyeva, N.- Otuzov 2008: 330)

Yene çıkdım daşarık "Yine çıktım dışarıya.” (Kara 1997: 458)

3.7. Düz-geniş /a/, /e/ ünlüleri ile biten fiillere “-an,-en” sıfat fiil ekleri getirildiğinde fiil kök ya da gövdesindeki düz-geniş ünlüler hece kaynaşması neticesinde uzar:

Köyneğim yelmeşyää derlään tenime “Gömleğim yapışıyor terleyen tenime. (Kara 1997: 404)

İişlään yerimizde ilkinci olup... “Çalıştığımız yerde birinci olup... (Kara 1997: 490).

Kääbir golyazmaları okaanıñda suv gısımlaan yaalı bolup galyaarsıñ. "Bazı müsveddeleri okuduğunda su avuçlamış gibi olursun.” (Govşudow 1989: 956). 
Tenimi parçalaan ol gara pençääñ / Eyesi / Kimdiğin bilebilmäändim. "Tenimi parçalayan o kara pençenin sahibinin kim olduğunu bilmemiştim.” (Gurbannepesov 1995: 3)

Hatda yerine düşendiğine-düşmäändiğine garamazdan, yazıcını̃ ööz yasaan sözleriniñem hemmesi üytgedilmään galdırıldı. "Hatta yerine uygun düşüp düşmediğine bakmadan / bakılmaksızın yazarın kendi ortaya koyduğu sözlerinin hepsi değiştirilmeden kaldırıldı.” (Gowşudow 1989: 958).

3.8. Düz-geniş /a/, /e/ ünlüleri ile biten fiillere "anda, -ende" zarf-fiil ekleri getirildiğinde fiil kök ya da gövdesindeki düz-geniş ünlüler hece kaynaşması neticesinde uzar:

Gülümsirääp okaanda gı1z / Toy gaazanna oocak gazdım. "Gülümseyip okuyunca kız / Düğün kazanına ocak yazdım.” (Kara 1997: 482)

Seni sallançakda üvräände eceñ / Eceñ yüreğine yürek ekenin. “Annen seni salıncakta salladığında / Annenin yüreğine yürekmişsin.” (Kara 1997: 480)

Maşıınıñ yelğini Mıradıñ yüzüne gözüne uranda ol mähnet tigriñ aşaağına düşerli bolup alcıraanda gapdalından 1lğaap gelenleriñ biiri onuñ goltuğından tutup alıp gaçd1. 'Kamyonun rüzgârı Murat'1n yüzüne gözüne vurduğu vakit o kocaman tekerleğin altına düşecek olup kendini kaybettiği anda yanından koşup gelenlerden biri onu koltuğundan tutarak alıp gitti.” (Kerbabayev 1992: 30)

İil yatar çenine golaylaanda, ol gaytmakçı boldı. "Halkın yatacağı vakit yaklaştığında o dönmek istedi.” (Govşudov 1989: 167)

Yaaşlığında dürdääne der dökmeseñ / İñ bolmaanda bir darağt ekmeseñ / Özüñden gör. "Gençliğinde inci gibi ter dökmesen / En azından bir ağaç dikmezsen / Kendinden gör.” (Kara 1997: 392)

3.9. İstek bildiren “-as1, -esi” eki, ünlü ile biten fillere getirildiğinde söz konusu ekin ünlüsü hece kaynaşması neticesinde uzar: 
Aağlaası gelmek “ağlayası gelmek”, çöplääsi gelmek "toplayası gelmek”, okaası gelmek “okuyası gelmek”, yörääsi gelmek “yürüyesi gelmek (Kara 2012: 29).

Naamıslı aadamlar şeyle gapılara zoor bilen getirilende de öözüni gizlääsi gelyäär. "Namuslu insanlar bu tür yerlere zorla getirildiğinde dahi kendisini gizleyesi geliyor (Gowşudow 1989: 341).

Yaaşadıkça / Yene yaaşaasıñ gelyäär "Yaşadıkça yaşayasın geliyor (Kara 1997:

İndi meniñ üçiin ağlaası iiş yook. "Şimdi benim için ağlanacak iş yok." (Deryayev 1981: 273)

Sen buu dünyää yañı inen mısaalı / Tääzeçe yaaşaasıñ / Söyesiñ geler. "Sen bu dünyaya henüz gelmiş gibi / Henüz yaşayasın / sevesin gelir.” (Ezizov 1995: 104)

3.10. Ünlü ile biten fiillere "-alı, -eli" zarf-fiil ekleri getirildiğinde hece kaynaşması neticesinde fiilin söz konusu ünlüsü uzar.

Dünyää dörääli bääri aadıñız aydım. "Dünya yaratıldığından günümüze adınız Türkü(dür) (Kara, 1997:488).

Oları̃ oğlanları yetişip, işlääp başlaalı bääri gurğunlaşıpdırlar. "Onları çocukları büyüyüp çalıştıklarından bu yana durumları düzelmiş.” (Kıyasova, G. Geldimiradov, A. -Durdiyev, H. 2015: 494)

\section{Ekleşme Durumunda Oluşan Uzun Ünlüler}

Türkmen Türkçesinde normalde uzun ünlülü olmayan bir ek uzun ünlülü olmayan sözcük kök ya da tabanına getirildiğinde ünlü uzamasına neden olan ünsüz düşmesi, ünsüz erimesi, ünlü düşmesi, ünlü karşılaşması, hece kaynaşması gibi bir ses olayı olmadığı halde sözcük kök ya da tabanındaki ünlünün uzadığ1 görülür. Bu şekilde oluşan ünlü uzunluklarını da birkaç grupta inceleyebiliriz: 
4.1. Ünlü ile biten sözcüklere teklik ve çokluk 1. ve 2. kişi iyelik eklerinin eklenmesi neticesinde iyelik eklerinden önceki ünlüler uzar:

Ataam, ataañ, ataamız, ataañız, göläämiz "buzağımız”, gölääñiz, yabıım "atım”, yabıñ, yabı1mız, yabıñ̃z, dürbiim "dürbünüm”, dürbiiñ, dürbiimiz, dürbiiñiz (TTS 1995: 10).

İkiimize bir öy besdir. "İkimize bir ev yeterli(dir).” (Durdıyewa 2006: 39)

Şeyde-şeyde bergiimizi tutuşlıgına üzeris. "Böylelikle borcumuzun tümünü öderiz.” (Durdiyewa 2006: 39)

Ey nuur-1 didääm! Bu nä sövdaadır? "Ey gözümün nuru! Bu ne sevdadır?” (Durdiyewa 2004: 22)

Tenimi parçalaan ol gara pençääñ / Eyesi / Kimdigin bilebilmäändim. "Tenimi parçalayan o kara pençenin sahibinin kim olduğunu bilmemiştim.” (Gurbannepesov 1995: 3)

“Mıhmaan ataañdan ulı” diyen atalar sözüni berk saklaap her kim mıhmaanlarıñ oturarına garaşyaardı. “ 'Misafir babandan ulu(dur)' denen atasözünü sıkıca koruyup bazıları misafirlerin oturmasını gözlüyordu.” (Govşudov 1989: 330)

Meniñ alıp bilmedik periimi oğlum alıpdır. "Benim alamadığım periyi oğlum almış.” (Kakalıyeva-Otuzov 1995: 46)

4.2. Ünlü ile biten sözcüklere ilgi ekinin eklenmesi durumunda ilgi ekinden önceki ünlüler uzar:

çaagaanıñ “çocuğun”, ogrınıñ "hırsızın”, döleeniñ "ahırın”, iniiniñ "kardeşin” (TTS 1995: 10-11).

Müñ duy̆̆ı̆ını̃̃, Müñ ahvaalıñ aadı baar "Bin duygunun, bin ahvalin adı var." (Kara 1997: 430)

Elkıssa, paatışaa wezir nesiihatını kabuul kılıp, ähli memleketini terk edip, hazıınaanıñ ıgtıyaarını wezirge berip we puukaraa libaasını geyip, rowzaayı- 
mutahharaaye Imam Rızaga çokunmaaga durd1. "Kısacası padişah vezirin nasihatlarını kabul edip bütün memleketi terk edip hazinenin sahipliğini vezire bırakıp yoksulluk elbisesini giyerek Ravza-yı Mutahhara'ya, İmam Rıza'ya baş vurmaya gitti. (Durdıyewa 2004: 9)

Suhan gat1 Mıraat aağaanıñ salamını almaan söwdaasını dowaam etdi. "Kat1 Suhan Mırat Ağabeyin selamını almadan alışverişine devam etti.” (Deryayev 1981: 44)

Uzuk garañkı giicääniñ içinde tövereğine garancaklaap gorka-gorka Berdiiniñ yaanına bardı. "Uzuk karanlık gecede çevresine bakınıp korka korka Berdi'nin yanına vard1.” (Deryayev 1981: 160)

4.3. Ünlü ile biten sözcüklere yükleme durum eki eklendiğinde söz konusu ekten önceki ünlüler uzar:

çaagaanı "çocuğu”, oğrını "hırsızı", döleeni "ahırı”, iniini "kardeşi” (TTS 1995: 10-11).

Başıña atyp sen, şaalı-tirmääni / Gözüňe çekip sen, gara sürmääni "Başına atmışsın şal1, ipekli örtüyü / Gözüne çekmişsin kara sürmeyi” (Durdıyewa 2004: 16).

... sen näämääni pikir edyääñ? "Sen neyi düşünüyorsun? (Kakalıyeva, N.Otuzov 2008: 61).

Yağşını yaatlamak elbetde govı. "Güzeli hatırlamak elbette iyi.” (Kara 1997:

Ayıbı yook, yatmaankaañ meniñ önüme bir goltuk göök yoruncaanı getirip dökersiñ. "Zararı yok, yatmadan benim önüme bir koltuk yeşil yoncayı getirip dökersin.” (Kakaliyeva-Otuzov 1995: 382)

Biiçäärääni görmäänime gatı kään vağt boldı. "Zavallıyı görmemem çok uzun bir süre oldu." (Govşudov 1989: 847)

Olar Uzuğı öye salandan gapıını yapıp gözeneğe gamış ayladılar. "Onlar Uzuk’u eve saldıklarında kapıyı örtüp evin ışıklığına kamış doladılar.” (Deryayev 1981: 67) 
Alıcı geçiini sınlaap durşuna satıcaa yüzlenip... “Alıcı keçiyi sınayıp dururken satıcıya yönelip...” (Çarıyev 2004: 84)

4.4. -mak, -mek isim-fiil eklerini almış fiillere yönelme durum eklerinin getirilmesi durumunda isim-fiil eklerinin ünlüleri uzar.

Okamaağa “okumağa”, iişlemääğe "çalışmağa” (TTS 1995: 11).

Sabaa olar, tagt üstüne haan çıkar, Gözlerimden yaaş ornuna gaan çykar, Yaara bir söz bildirmääğe caan çıkar, Ata-ene, maña gurbat eyleyiñ! 'Sabah olur taht üstüne han çıkar / Gözlerimden yaş yerine kan çıkar / Sevgiliye bir söz iletmeğe can çıkar / Baba- ana bana güç kuvvet verin (Durdıyewa 2004: 24).

Veli kel yaalı oynatğı garakçıını tapar daa "sen serdaar, sen baatır" diyen bolup, oynar daa paraahat oturan iili çapmaağa iiberer. "Veli kel gibi maskara hırsızı bulup "sen başkan, sen yiğit" diyerek huzurlu yaşayan halkı baskına gönderir." (Govşudov 1989: 21)

Öözem yumşunı aytmaağa gezmezden önürti yene Gutlımıraadıñ aağırılı yerinden tutd1. "Kendisi de vazifesini söylemeden önce yine Gutlımırat'ın hassas yerinden yakaladı." (Govşudov 1989: 152)

Bir gün ecesi öyde uuklaap yatırkaa, oğlan ecesiniñ saçından yedi gat caayıñ açarını alıp, tamları açmaağa başlaapdır. "Bir gün annesi evde yatarken oğlan annesinin saçından yedi katlı evin anahtarını alıp, evleri açmaya başlamış." (Kakalıyeva-Otuzov 1995: 40)

Bir gün Amanıñ öözünden ulı aağası bilen uyası mekdepden gelip, iyip-içip, dınç alanlarından soñ sapaklarını okamaağa oturdılar. "Bir gün Aman'ın ağabeyi ile kız kardeşi gelip, yiyip içip dinlendikten sonra derslerine çalışmaya başladılar." (Kerbabayev 1992: 20)

4.5. Bulunma durum eklerine $+\mathrm{k}$, $+\mathrm{ki}$ aitlik eklerinin eklenmesi halinde bulunma durum eklerinin ünlüleri uzar: 
Deryaanıñ pılaan yerindääki güzerden atlarını suwa yakyaarlar. "Irmağın falan yerindeki geçitten atlarına su içiriyorlar.” (Kakalıyeva, N.- Otuzov 2008: 247)

Biraaz salımdan Garasatlık yaanındaakı yoldaşlarına aydyaar: "Bir süre sonra Garasatlık yanındaki yoldaşlarına söylüyor.” (Çarıyew 2004: 34)

Öyüñ gapdalındaakı kümede yatan kanı baatır hem atıñ sesini eşidenden bir zaadıñ bolanını aañıp 1lgaap daş çıkdı. "Evin önündeki kulübe de yatan Kanı Batır da atın sesini işittiğinde bir şeylerin olduğunu anlayıp koşturarak dışarı çıktı." (Govşudov 1989: 159)

İndi mañlayımızdaakını görüp, ertiire çenli sabır etmeğimiz gerek. "Şimdi alnımızda yazılı olanı görüp, sabaha kadar sabır etmeliyiz.” (Govşudov 1989: 77)

Stepan oylanıp oturışına kääsesindääki çaayı içti. "Stepan düşünüp dururken kâsesindeki çayı içti.” (Govşudov 1989: 461)

Çöplügiñ içindääki dıza golaylaan çı1glı göök otlarıñ 11sı Çerkeziñ burnuna urd1, onı asğırdarlı bold1. "Ağaçlığın içindeki dize kadar uzayan taze yeşil otların kokusu Çerkez'in burnuna vurdu, onu hapşıracak oldu.” (Kerbabayev 1992: 113)

4.6. Vasita ekinin de ekleşme durumunda kendisinden önceki ünlüyü uzattığ1 görülür:

arkaan : "arka üstü”, eliin " kendi eliyle, bizzat”, güniin "bir gün, bir günde” günortaan “öğlen, öğleyin”, gışın, yaazıın “yaz kış”, gizliin “gizlice”, götiin “ geriye, geri, arkasına”, ikindiin "ikindi ile akşam arası”, yüziiin “yüzüstü”, biriin biriin "birer birer" (TTS 1995: 9)

Dañdan iişe gidip yassın gaydardı. "Şafaktan işe gidip yatsı vakti dönerdi." (Gurbannepesow 1995: 109)

Gözüniñ gıtağın aylayaar ene. "Gözünün ucuyla bakıyor anne.” (Kara 1997: 552) 
Perii Jahan päälwaanı arkaan yatırıp, gözleri yerli-yerinde goyupdır. "Peri Jahan pehlivanı sırtüstü yatırıp yerli yerinde bırakmış." (Kakaliyeva, N.- Otuzov 2008: 183)

\section{Daima Uzun Ünlülü Ekler}

Türkmen Türkçesinde yukarıda bahsettiğimiz ekler ekleşme sonrasında oluşurken bazı eklerin daima uzun ünlülü oldukları görülür. Türk dilinin tarihi dönemlerinde kısa ünlülü olan bu ekler sonradan uzun ünlülü olmuşlardır. $\mathrm{Bu}$ tür uzun ünlülerin ilk planda konuşma diline ait bir söyleyiş özelliği olarak çoğu zaman pekiştirme amacıyla kullanıldıklarını, yazı diline daha sonradan aktarıldıklarını söyleyebiliriz. Türkmen Türkçesinde daima uzun ünlülü telaffuz edilen ekleri ve sözcükleri birkaç başlık altında incelemeyi uygun gördük.

5.1. Karş1laştırma eki “+rak, +rek” Türkmen Türkçesinde daima uzun ünlülüdür:

gowıraak "daha güzel”, kiçirääk "daha küçük”. (TTS 1995: 9)

Bir oobada samsıgraak yigit baar eken. "Bir köyde aptalca bir yiğit varmış." (Çarıyew 2004: 51)

Hany, heley, tiizrääk bol-da, äýnegimi äber - diýipdir. "Hani, hanım, çabuk ol da gözlüğümü alıver, demiş. (Durdıyewa 2006: 144)

Yaz köpürääk yene de! / Vağt garaşmaz. "Yaz çokça yine / Vakit beklemez (Kara 1997: 422)

5.2. Şüphe bildiren “-kaa, -kää” edatı Türkmen Türkçesinde daima uzun ünlülüdür. Gelen kimkää "Gelen kim acaba", Kino gızıklımıkaa "Sinema ilginç mi acaba?" (TTS 1995: 10)

Sen ööz atlıları̃ bilen 11za gitseñ nähiili bolarkaa? - diydi. "Sen kendi atlıların ile arkaya gitsen nasıl olur ki?" (Gowşudow 1989: 25) 
Aanna gününiñ gelenini men neneñsi bilerkääm? "Ben cuma gününün geldiğini nasıl bilebilirim ki?" (Durdiyewa 2006: 20)

Kimiñ haypı geldikää buu haalıma. "Kim acıdı ki bu hâlime?” (Kara 1997: 434).

O1 nääme üçiin çaağırdı-kaa “O niçin çağırdı ki?” (Borcakov, A. - Sarıhanov, M. - Söyegov, M. - Hocayev, B. - Ärnazarov, S. 2000: 407-532)

Soñı näähiili gutarar kaa? "Sonu nasıl biter ki?" (Borcakov, A. - Sarıhanov, M. - Söyegov, M. - Hocayev, B. - Ärnazarov, S. 2000: 407-532)

5.3. Pekiştirme edatı "-aa, -ää ve daa" Türkmen Türkçesinde daima uzun ünlülüdür:

Sapar-aa geldi. “Sapar da geldi.”, men-ää “ben de” (TTS 1995: 10).

Menden ää yüz övürdi. "Benden artık yüz çevirdi.” (Kara 1997: 116)

Men ää ozalam Öwezmırat baatırdan gorkup duramook. "Ben de önceleri Övezmurat Batır'dan korkmuyorum.” (Govşudow 1989:75)

Men-ää seniñ yüreğiñ / Uruşunı eşitdim. "Ben de senin yüreğinin / Vuruşunu işittim." (Kara 1997: 436)

Siz maña yool harcı tapıp berin dää. "Siz bana yolluk buluverin da." (Borcakov, A. - Sarıhanov, M. - Söyegov, M. - Hocayev, B. - Ärnazarov, S. 2000: 407-534)

Ataam onda düşündir-dää. "Babacığım o zaman anlat da." (Borcakov, A. Sarıhanov, M. - Söyegov, M. - Hocayev, B. - Ärnazarov, S. 2000: 407-534)

Vah, Göroğlı, men onı biirinden nesye alıpdım-daa "Ah Köroğlu, ben onu birinden parasız almıştım da.” (Borcakov, A. - Sarıhanov, M. - Söyegov, M. Hocayev, B. - Ärnazarov, S. 2000: 407-537) 


\section{Sözcük Birleşmeleri Neticesinde Oluşan Uzun Ünlüler}

Sözcük birleşmeleri neticesinde oluşan uzunlukların değişik nedenleri göze çarpar. Bu gruptaki uzunlukların bir kısmında ünlü karşılaşmalarının etkisi söz konusudur. Ünlü ile biten bir sözcük, ünlü ile başlayan başka bir sözcüğün ünlüsüyle birleștiği zaman iki ünlüden biri düşer. Kalan ünlü düşen ünlünün yükünü üstlendiğinden ünlü uzaması gerçekleşir:

Trkm.T. ertiir < erte+ir.

Sözcük birleşmeleri neticesinde oluşan uzunlukların bir kısmında ise ses düşmelerinin etkisi söz konusudur. Sözcük birleşmeleri neticesinde yarım ünlü değerindeki ünsüzlerin erimesi neticesinde ilk planda ünlü karşılaşması gerçekleşir. Oluşan ünlü karşılaşmaları neticesinde birleşen ünlülerin uzun ünlü teşkil ettiği görülür:

Trkm.T. bäärik $<$ bu + yer + ik, Trkm.T. düyn $<$ tün+gün, Trkm.T. öññiin “önceki gün” < öñki + gün, Trkm.T. öññil "önceki yıl” < öñki + yıl; Trkm.T. tarpataayın "aniden, birdenbire" $<$ Ar. turfetu'l 'ayn; Trkm.T. iibermek $<1$ d - 1 - ber-.

6.1. Şimdiki zaman eki “-yaar, -yäär” Türkmen Türkçesinde uzun ünlülüdür. Özellikle batı grubu Türk lehçelerinde kullanılan "yor, yAAr" şimdiki zaman eklerinin oluşumu ile ilgili değişik görüşler vardır. Bu görüşlerden ilki Meninski'ye aittir. Şimdiki zaman ekinin "yort-" fiiline getirilen /r/ geniş zaman şeklinin ekleşmesi neticesinde oluştuğunu belirtir. (Meninskiy 1680). Bu görüşlerden ikincisi F.E. Korş’a aittir. Korş şimdiki zaman ekinin "yat-" fiilinden geniş zaman eki ile yapılan "yatur" şimdiki zaman sıfat-fiilinden oluştuğunu belirtir. /t/ sesinin düşmesi neticesinde şeklin zamanla yaur > yAAr, -yor şekillerine dönüştüğünü belirtir (Korş 1907: 7). Şimdiki zaman ekinin oluşumu ile ilgili üçüncü görüş de N. İ. İlminskiy'e aittir. İlminskiy şimdiki zaman ekinin "dur-" yardımcı fiilinden geldiğini belirtir. Yardımcı fiil olarak fiillerin birleşik şekillerinde kullanılan "dur-” yardımcı fiilinin ünsüzünün zamanla akıc1 /y/ ünsüzüne dönüşmesi neticesinde oluştuğunu belirtir. Keledür "o gelir" şeklindeki sözcük zamanla geleyür şekline dönüştüğünü belirtir. (İlminskiy 1860). 
Şimdiki zaman eki Batı grubu Türk lehçelerinden Türkiye Türkçesi ile Türkmen Türkçesinin tarihi dönemlerinde sürerlilik ifade eden "yorı-" tasvir fiilinin geniş zaman çekiminden hece yutumu neticesinde (al-a yoru-r $>$ al(I)yor, başla-y-u yoru-r $>$ başl1yor) ortaya çıktığı görülür (Banguoğlu 1959: 464; Ergin 1995: 459; Korkmaz 2003: 548; Nartıyev 2010: 162; Türk 1999: 313). Bu ekleşme neticesinde düşen seslerin yükünü üstlenen ünlülerin uzadığı görülür:

Baryaar "gidiyor”, gelyäär "geliyor” (TTS 1995: 9).

Satıgçı soorayaar: Almamı, naar mı? "Satıcı soruyor: Elma mı nar mı?" (Gurbannepesow 1995: 214)

Biziñ aaraamıza sokulyaar seytaan. "Bizim aramıza sokuluyor şeytan" (Kara 1997: 112).

Zülpi zerefşaanım gelyäär. "Saçları altın sarısı (sevgilim) geliyor.” (Zelili 1991: 3)

Kanı baatır Permaanıñ önüne düşüp eğlenmään gidip oturışına kääyerde oña sooră̆ beryäär. “Kanı Batır Perman'ın önüne düşüp oyalanmadan giderken bazı yerlerde ona soru sorar.” (Govşudov 1989: 811)

Eğer almasañ meniñ oon döört yaaşayaançaam eden günääm seniñ boynunadiyyäär. "Eğer almasan benim on dört yaşına kadar edindiğim günahlarım senin boynuna- diyor.” (Kakaliyeva-Otuzov 1995: 421)

Kääbir golyazmaları okaanıñda suv gısımlaan yaalı bolup galyaarsıñ. "Bazı müsveddeleri okuduğunda su avuçlamış gibi olursun.” (Govşudow 1989: 956)

6.2. "goy-" yardımcı fiili ile kurulan birleşik fiiller: Bu yardımcı fiil, birleşik fiil teşkil ettiğinde sözcükteki ses düşmeleri neticesinde getirildiği fiile "-aay, ääy" şekillerinde bağlanır ve emir, istek, tezlik gibi değişik işlevler üstlenir (Dinç 2014: 132137; Azmun 1990: 91). Bu ek Türkmen Türkçesinde daima uzun ünlülüdür: baraayadım “Keşke gitseydim.”; gelääyedim “keşke gelseydim.” (TTS 1995: 9) 
Imaam Rıza men saña gelääysem / Gam, gussalardan elim üzääysem / Yetiban yaarın haalın bilääysem / Çaarıyaar yetişsin daadıma meniñ. "İmam Rıza ben sana gelirsem / Gam ve kederden elimi çekersem / Ulaşıp yârin halini bilirsem / Çarıyar yetişsin imdadıma benim. (Durdıyewa 2004: 124).

Eger indi gaydıp gapımdan gelääyseñ hökmaan çaparıñ. "Eğer şimdi dönüp kapımdan gelirsen (seni) mutlaka öldürürüm.” ( Gowşudow 1989: 325)

6.3. Sifat-fiil eki “-yaan, -yään” Türkmen Türkçesinde daima uzun ünlülüdür: “yaan, -yään"sıfat-fiil eki Türkmen Türkçesinde çeşitli eklerin birleşip ekleşmesi neticesinde oluşmuştur. Bu ek “-a/e, -1p/ip” zarf-fiil ekine "yor1-, yöre-” fiili ve -an/en sıfat-fiil eklerinin getirilmesi ve sonrasında şeklin birleşip kalıplaşması neticesinde oluşmuştur: alıp yörgen > alayörgen > alyaan" gibi (Borcakov, A. - Sarıhanov, M. Söyegov, M. - Hocayev, B. - Ärnazarov, S. 2000: 407-408).

baryaan “giden”, gelyään “gelen” (TTS 1995: 9).

Yigrimi yıl bääri şol yazyaan bolsan. "Yirmi yıldan beri yazmış isen." (Kara 1997: 132)

Bugday ekyään oña jogaap bermään gidiberipdir. "Buğday eken ona cevap vemeden gidivermiş.” (Çarıyew 2008: 8)

Gaýdyp gelyään gelniñ gaaynyna: - Gelniñ gelyäär, dayza - diyip buşlaapdırlar. "Dönüp gelen gelinin kaynına: -'Gelinin geliyor' diye müjdelemişler (Çarıyew 2004: 50).

6.4. “-aağada, ääğede” zarf-fiil eki Türkmen Türkçesinde uzun ünlülüdür: Bu zarf-fiil eki de ekleşme neticesinde oluşmuş bir ektir. Türkmen Türkçesinde bu ekin “ıp, -ip zarf-fiil ekinin, "gel-" yardımcı fiilinin ve "de/da" son çekim edatlarının getirilip birleşmesi neticesinde oluştuğu belirtilir (Borcakov, A. - Sarıhanov, M. - Söyegov, M. - Hocayev, B. - Ärnazarov, S. 2000: 447).

baraağada "gider gitmez”, görääğede “görür görmez. (TTS.,1995:10) 
Baaraağada buldozere / Atlan diyyää goca gövün. "Varır varmaz buldozere / Atla diyor koca gönül.” (Kara 1997: 618)

Nääme üçiindir, meni ayaklarım şo tarapa çekdi, baraağada gapıını açdım. "Nedendir, ayaklarım beni o taraf çekti, varır varmaz kapıyı açtım." (Govşudov 1989: $56)$.

Ay bi turşı ekeni diyääğe de, onu kaakasınıñ eline tutdurıp, beyleki yaanlıgıñ ağzını çözyäär. "Ay bu bir turşuymuş diyerek onu babasının eline tutuşturup, beri taraftaki küpün ağzını çözer.” (Çarıyev 2004: 40)

Nuurmäämmet yañkı saapından berk gısımlaap duran pıçağını görkezääğede: Men mı1hmaanlarımı uğratman- diydi. "Nurmuhammet deminki sıkıca avuçladı̆̆ bıçağını gösterirken: ‘Ben konuklarımı göndermem.' dedi.” (Deryayev 1981:224)

Inhaa oğlanlarım..diydi de Mıraat aağa burnunı çekip, köönece telpeğinden kirlice yağlığını alaağada, sakğalsayı dökülen gözyaşını süpürdi, yüzünü aşaak salıp, birsalım geplemään oturdı. "İşte çocuklarım, dedi de Murat Ağabey burununu çekip, eskiyen kasketini, kirlice mendilini alırken sakalına kadar dökülen gözyaşını sildi, yüzünü aşağ1 sald1, bir süre konuşmadan oturdu.” (Deryayev 1981: 239)

Sar1 onuñ kellesini goltuğınıñ aşağına dolaap puğta gısaağada, aşaak eğdi. “Sarı onun kafasını koltuğuna kısıp sıkıca sıkıştırırken aşağı eğdi.” (Deryayev 1981: 303)

\section{Ayınlı ve Hemzeli Uzunluklar}

Türkiye Türkçesinde olduğu gibi (Tekin 1958: 110-113) Türkmen Türkçesinde de bünyesinde ayın " $ع "$ ve hemze "๕" bulunan sözcüklerdeki ünlülerin uzadığ1 görülür: Trkm.T. määde (TDS. mäde) "mide" < Ar. mi de; Trkm.T. möömin “mümin" < Ar. mü’min; Trkm.T. määlim (TDS. mälim) "malum" < Ar. ma'lûm; Trkm.T. tääsiir “teesir" < Ar. te'siir; Trkm.T. näälet "lanet" < Ar. la net; TrkmT. daawaa "dava" < Ar. 
da 'vâ; TrkmT. maayıp "hastalıklı, sakat" < Ar. ma'yûb "ayıplı, ayıplanan, kusurlu" TrkmT. tamaa $<$ Ar. tama .

\section{Sonuç}

Türkmen Türkçesinde Ana Türkçedeki aslî uzun ünlüler büyük oranda korunmuştur. Bununla birlikte sözcük köklerinde ve kök-ek birleşmeleri durumunda çeşitli ses olayları neticesinde oluşan ikincil uzun ünlülerin de oranı oldukça fazladır. Türkmen Türkçesinde değişik nedenlerle sonradan oluşan ikincil uzun ünlüleri birkaç başlık altında ele alınabilir. Bu ünlülerden bir kısmı ünsüz yitimi sonucu oluşmuştur: kööne "eski" < Far. kohne, määkääm "muhkem" < Ar. muḥkem, määtääç "muhtaç" < Ar. muḥtâc, yaalı < ET. yañlıg; , miive "meyve" < Far. meyve, şıһ̆ "şeyh" < Ar. şeyh, zinnat "ziynet" < Ar. ziiynet.

İkincil uzun ünlülerin bir kısmı hece kaynaşması neticesinde oluşmuştur: käähüda "kethüda" < Far. ked + hudâ, uuk1 "uyku" $<$ ET. ud1- +ku; TrkmT. paataa TT. fatiha < Ar. fâttiha; tääret "taharet, temizlik $<$ Ar. țahâret; baatır $<$ Moğ. Baġatur.

İkincil uzun ünlülerin bir kısmı ünlü karşılaşması neticesinde oluşmuştur: gayaa "kayaya”, gapaa "kapıya”; okaayın “okuyayayım”, okaalın / okaalı "okuyalım”, okaap “okuyup”, işlääp “çalışıp” okaası gelmek “okuyası gelmek”, yörääsi gelmek "yürüyesi gelmek"... gibi.

İkincil uzun ünlülerin bir kısmı ise ekleşme neticesinde oluşmuştur: ataam "ataañ, ataamız, ataañız, göläämiz "buzağımız”, çaagaanıñ “çocuğun”, ogrınıñ "hırsızın”, döleeniñ “ahırın”, çaagaanı “çocuğu”, ogrını "hırsızı”, döleeni “ahırı”, iniini "kardeşi”... gibi.

Diğer Türk lehçelerinde kısa ünlülü olan eklerin bir kısmı Türkmen Türkçesinde daima uzun ünlülü kullanılagelmiştir: gowıraak “daha güzel”, kiçirääk “daha küçük”... gibi. 
Türkmen Türkçesinde ikincil uzun ünlülerin bir kısmı sözcük birleşmeleri neticesinde oluşmuştur: ertiir < erte+ir; öññiin “önceki gün” < öñki+gün, öññiil “önceki yıl” < öñki + yıl; tarpa-taayın "aniden, birdenbire” < Ar. turfetu'l 'ayn ... gibi.

Türkmen Türkçesinde ikincil uzun ünlülerin diğer bir kısmı ise ayınlı ve hemzeli seslerin uzun ünlülere dönüşmesi neticesinde oluşmuştur: määde (TDS. mäde) "mide" < Ar. mi 'de, möömin “mümin” < Ar. mü’min, määlim (TDS. mälim) "malum” < Ar. ma 'lûm, tääsiir "teesir" < Ar. te'siir, näälet "lanet" < Ar. la'net; TrkmT. daawaa TT. dava < Ar. da'vâ; TrkmT. maayıp "hastalıklı, sakat" < Ar. ma yûb "ayıplı, ayıplanan, kusurlu". 


\section{KAYNAKÇA}

ATANIYAZOV, Soltanşa (2004). Türkmen Dilinin Sözköki Sözlügi, Aşgabat.

AZMUN, Yusuf (1983). Ana Çizgileriyle Türkmence Dilbilgisi, Cilt I (Ses Bilgisi), Ankara: Ankara Ü. Dil ve Tarih Coğrafya Fak. Yayınları.

AZMUN, Yusuf (1990). “Türkmence Asli ve Dolaylı Uzun Ünlüler”, Journal of Turkish Studies (Türklük Bilgisi Araştırmaları Dergisi), Center For Middle East Studies of Harvard University, Volume 14: 75-94.

BORCAKOV, A.; - SARIHANOV, M.; - SÖYEGOV, M.; - HOCAYEV, B.; ÄRNAZAROV, S. (2000). Türkmen Diliniñ Grammatikası (Morfologiya), Aşğabat: Türkmenistanıñ Prezidentiniñ Yanındakı Ilım ve Tehnika Baradakı Yokarı Geñeş Mağtımğulı Adındakı Dil ve Edebiyat İnstitutı.

BURAN Ahmet; ALKAYA Ercan; YALÇIN, Süleyman Kaan (2014). Çăgdaş Türk Yazı Dilleri (Güneybatı / Oğuz Grubu), Ankara: Akçağ Yayınları

BURAN, Ahmet (2006). "Çağdaş Türk Yazı Dillerinde ve Türkiye Türkçesi Ağızlarında İkincil Uzun Ünlüler”, II. Kayseri ve Yöresi Kültür, Sanat ve Edebiyat Bilgi Şöleni, Kayseri, 10-12 Nisan 2006.

CLAUSON, Sir Gerard (1972). An Etymological Dictionary of Pre-Thirteenth Century Turkish, Oxford: Oxford University Press. Wiesbaden.

CLARK, Larry (1998). Turkmen Referrence Grammar, Otto Harrassowitz,

ÇARIYEW, Orazgılıç (2004). Türkmen Şorta Sözleri, Türkmenistanıñ Milli Medeniyyet "Miras" Merkezi, Aşgabat: Türkmenbaşı Adındakı Türkmenistan Milli Golyazmaları İnstitutı.

DEVELLIOĞLU, Ferit (1993). Osmanlıca-Türkçe Ansiklopedik Lûgat, Ankara: Aydın Kitabevi Yayınları.

DERYAYEV, Hidır (1983), Ikbal, Aşğabat.

DOĞAN, Levent (2012). Türkmen Atasözleri, İstanbul: Kriter Yayınları.

DURDIYEWA, Amangül (2004). Aslı Kerem (Türkmen Halk Destanı), Türkmenistanıñ Milli Medeniyyet "Miras" Merkezi, Aşğabat: Türkmenbaşı Adındakı Türkmenistan Milli Golyazmaları İnstıtutı.

DURDIYEWA, Amangül (2006). Ependi, Türkmenistanı̃ Milli Medeniyyet "Miras" Merkezi, Aşğabat: Türkmenbaşı Adındakı Türkmenistan Milli Golyazmaları Institut1.

ESENMEDOVA, Amangül (2010). Häzirki Zaman Türkmen Dili (Morfologiya), Aşğabat: Türkmenistanıñ Bilim Ministirliği Mağtımğulı Adındakı Dövlet Üniversiteti.

GOWŞUDOW, Ata (1989). Perman, Aşğabat: Türkmenistan Neşiryatı. 
GURBANNEPESOV, Kerim (1995). Oylanma Bayrl, Aşğabat: Türkmen Döwlet Neşiryat Gulluğ1.

GÜLENSOY, Tuncer (2007). Türkiye Türkçesindeki Türkçe Sözcüklerin Köken Bilgisi Sözlüğ̈̈, Ankara: Türk Dil Kurumu Yayınları.

HAMZAYEVA, M. Ya. (1962). Slovarı Turkmenskogo Yazıka, Aşhabad: Akademiya Nauk Turkmenkoy SSP İnstitut Yazıkoznanıy.

HANSER, Oskar (2003). Türkmence El Kitabı, çev. Zühal Karg1 Ölmez, Türk Dilleri Araştırmaları Dizisi 17, İstanbul: Kitap Matbaası.

İLMINCKY N. (1860). Ueber die Sprache der Turkmenen. Aus einem Briefe des Herrn Ilminsky an A.Schiefner.- Bulletin de I "Academie imperiale des sciences de St. Peterbourg". T. I. SPb.

KAKALIYEVA, N.; OTUZOV, S. (2008). Türkmen Halk Ertekileri, Aşğabat: Türkmenistanıñ Prezidentiniñ Yanındakı Ilım ve Tehnika Baradakı Yokarı Geñeş Mağtımğulı Adındakı Dil ve Edebiyat İnstitutı.

KAHTALI SİS, Nesrin (1995). Nuhun Tupanı, (Yayımlanmamış Doktora Tezi), İnönü Üniversitesi, Sosyal Bilimler Enstitüsü, Malatya.

KARA, Mehmet (1997). Ata Atacanov'un Şiirleri I-II, Ankara: Türk Dil Kurumu Yayınları. Yayınlar1.

KARA, Mehmet (2012). Türkmen Türkçesi Grameri, İstanbul: Etkileşim

KERBABAYEW, Berdi (1992). Saylanan Eserler (Hèkayalar, Powestler we Folklor), Aşgabat: Magarıf.

KIYASOVA, G.; GELDIMIRADOV, A.; DURDIYEV H. (2016). Türkmen Diliniñ Düşündirişli Sözlüği, Cilt II, Aşğabat: Türkmenistanıñ Ilımlar Akademiyası Mağtımğulı Adındakı Dil ve Edebiyat İnstitutı.

KORKMAZ, Zeynep (2017). Türkiye Türkçesi Grameri: Şekil Bilgisi, 5. Bask1, Ankara: Türk Dil Kurumu Yayınları.

KORŞ, F. E. (1907). Proishodjeniye formı nastoyaşçego vremeni v zapadnoturyetskih yazıkah.

MENINSKİ F. (1680). Linguarum orietalium Turcicae, Arabicae, Visdobonae: Persicae institutiones, sen Grammatica Turcica.

TEKIN, Talat (1958). "Ayınlı ve Hemzeli Kelimeler”, Türk Dili, Dil ve Edebiyat Dergisi, C.VIII, 86: 110-113.

TEKIN, Talat; ÖLMEZ Mehmet; CEYLAN Emine; ÖLMEZ Zuhal ve Süer EKER (1995). Türkmence-Türkçe Sözlük, Ankara: Simurg Kitapçılık. 
Engin GÖKÇÜR, “Türkmen Türkçesinde İkincil Uzun Ünlüler Üzerine”, Mavi Atlas, 5(2)/2017: 549-576.

TIETZE, Andreas (2002- 2009). Tarihi ve Etimolojik Türkiye Türkçesi Lugatı, Birinci Cilt: A-E, İstanbul: Simurg Yayınları; İkinci Cilt F-J, Viyana: Österreichische Akademie der Wissenschaften.

TÜRK Vahit (1999). “Türkçede Şimdiki Zaman Kavramı, Çekimleri ve Ekleri”, Türk Dünyası Araştırmaları, 10: 291-340.

Türk Dil Kurumu (2009). Türkçe Sözlük, Ankara: Türk Dil Kurumu Yayınları.

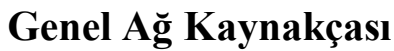

http://enedilim.com/sozluk/soz

http://hazynasozluk.com/sözlük

http://www.tdk.gov.tr 